Bangl. J. Vet. Med. (2017). 15 (2): 141-146

ISSN: 1729-7893 (Print), 2308-0922 (Online)

\title{
ANTIMICROBIAL RESISTANCE OF ESCHERICHIA COLI ISOLATED FROM MILK, BEEF AND CHICKEN MEAT IN BANGLADESH
}

\author{
M. A. Rahman ${ }^{1,2}$, A. K. M. A. Rahman', M. A. $\operatorname{Islam}^{3}$, M. M. Alam ${ }^{1 *}$ \\ ${ }^{1}$ Department of Medicine, Faculty of Veterinary Science, Bangladesh Agricultural University, Mymensingh-2202, \\ Bangladesh: ${ }^{2}$ Department of Medicine, Surgery and Obstetrics, Patuakhali Science and Technology University, Babugonj, \\ Barisal, Bangladesh; ${ }^{3}$ Department of Microbiology and Hygiene, Bangladesh Agricultural University, Mymensingh-2202, \\ Bangladesh
}

\begin{abstract}
Food-borne pathogens causing infections and intoxications can affect everyone. Escherichia $(E)$ coli is one of the major food borne bacterial pathogens. This study was conducted to investigate the prevalence of E. coli in milk, chicken meat and beef and to determine the multi-drug resistance profile of $E$. coli in Mymensingh district, Bangladesh. A total of 169 samples including milk (n=108), chicken meat (n=51) and beef $(n=10)$ were collected from Bangladesh Agricultural University (BAU) dairy farm, American dairy farm, Gazipur and retail markets of municipal area during July 2016 to June 2017. E. coli were isolated and identified by colony characteristics on selective agar like Eosine-methylene blue (EMB) agar, Salmonella-Shigella (SS) agar, Gram staining, biochemical test and Polymerase Chain Reaction (PCR). The overall prevalence of $E$. coli in all food samples was 37.86\%. A total of $32(29.63 \%)$ milk, $25(49.02 \%)$ chicken meat and 07 (70\%) beef samples were E. coli positive through conventional method. Among 64 samples only 23 samples (35.94\%) were confirmed by PCR. Multi-drug resistant E. coli were detected by disc diffusion test using 10 commonly used antibiotics. Antibiogram study showed that $E$. coli isolated from chicken meat were resistant to oxytetracycline (92\%), sulphonamide-trimethoprim (84\%), amoxycillin (76\%) and erythromycin (60\%). E. coli isolated from beef sample were resistant to erythromycin $(85.71 \%)$ and oxytetracycline $(71.43 \%)$ and sensitive to ciprofloxacin $(100 \%)$, gentamicin $(100 \%)$ and neomycin $(100 \%)$. However, all isolates of $E$. coli were found sensitive to amikacin $(100 \%)$. E. coli isolated from milk sample were $100 \%$ sensitive to gentamicin followed by neomycin, ciprofloxacin, azithromycin, oxytetracycline and erythromycin. Overall $50 \%$ of $E$. coli isolates of food were found multi-drug resistant. About $28.13 \%, 57.14 \%$ and $76 \%$ of the $E$. coli isolates originated from milk, beef and chicken meat respectively were multi-drug resistant. The higher prevalence of $E$. coli in chicken meat, beef and milk indicates unhygienic production and processing of these foods. Presence of multi-drug resistant $E$. coli in these foods might pose serious public health threats. The antibiogram profile of the isolates will help therapeutic decision making in the treatment of colibacillosis in cattle and poultry in Bangladesh.
\end{abstract}

Keywords: E. coli, milk, beef and chicken meat, antibiogram, multidrug resistance, PCR.

\section{INTRODUCTION}

Foods of animal origin like chicken meat, beef and milk are rich in proteins which are very essential to body growth and development. However, foods of animal origin also act as a vehicle and medium to transmit various microorganism causing health hazards, disease and death. Food borne diseases are a growing public health problem all over the world which cause an estimated 48 million illnesses and 3,000 deaths each year in the United States (Scallan et al., 2011). In developed countries, up to $30 \%$ of the population suffer from food borne diseases each year, whereas in developing countries up to 2 million deaths are estimated per year (WHO, 2007a, b).

E. coli is one of the major food borne bacterial pathogen. Majority of the E. coli are non-pathogenic but few of them are highly pathogenic causing watery and bloody diarrohea e.g., E. coli 0157:H7 which is associated with life threatening disease such as hemorrhagic colitis, hemolytic uremic syndrome and thrombotic thrombocytopenic purpura. Raw milk is considered a high-risk food as it is highly nutritious and serves as an ideal medium for bacterial growth. Several factors are responsible for milk contamination such as poor hygienic milking conditions, contaminated equipment, milking utensils and milk handlers with poor personal hygiene (Mohamed et al., 2014).

E. coli is most common species of facultative anaerobe found in the Gastro-Intestinal tract of both man and animals and the most commonly encountered pathogen in the Enterobacteriaceae family, therefore the presence of such organism in foods is the indication of fecal contamination (Mohamed et al., 2014). Due to the increase consumption chicken, milk and beef, the risk of exposure to various animal origin pathogens such as pathogenic E. coli has also increased (Shivani et al., 2014; Lisa, 2013).

Food is also an important factor for the transfer of antimicrobial resistance. Such transfer can occur by means of residues of antibiotics in food like poultry meat (Jhonson et al., 2007), through the transfer of resistant food-borne pathogens or through the ingestion of resistant strains of the original food microflora and resistance transfer to pathogenic microorganisms (Pesavento et al., 2007). In the process of food production many kinds of antimicrobials are used for preventing and controlling diseases, enhancing growth and increasing feed efficiency in food producing animals (CDC, 2005). Due to the indiscriminate uses of antibiotics and agricultural use of antimicrobials (David et al., 2002) the incidence of multiple drugs resistance in E. coli has been increased (Khan et al., 2005; Sharada et al., 2010).

*Corresponding e-mail address: asamahbub2003@yahoo.com 


\section{A. Rahman and others}

Bangladesh is a densely populated agricultural country with $>160$ million and most of them have close interaction with animals. Salauddin (2015) isolated E. coli in all the samples of broiler and found some isolates of E. coli were multi drug resistant. Islam et al. (2010) characterize shiga-toxin producing Escherichia coli in raw meat, raw milk in Bangladesh .Food borne diseases including colibacillosis are a significant and widespread global public health threat reported in Bangladesh (Samad, 2011; Zakaria et al., 2011). Hence the objectives of this study were to isolate and identify antimicrobial resistant E. coli from chicken meat, beef and milk samples in Bangladesh.

\section{MATERIALS AND METHODS \\ Collection of samples}

The samples were collected randomly from farms and local markets situated in Mymensingh and Gazipur district of Bangladesh. A total of 169 (51 poultry meat, 10 beef and 80 milk) samples have been tested from July 2016 to June 2017. Aseptically collected meat samples have been placed in sterile plastic bags and then brought to the Medicine laboratory of veterinary science at BAU using icebox. Milk samples have been collected from BAU dairy farm, American dairy farm, Gazipur, surrounding other local farm and market. Aseptically 8-10 ml of milk was collected in test tube directly from teat of lactating cow and local market and send to the Medicine laboratory using icebox. Five to ten grams of chicken breast meat or beef were collected aseptically in zipper bag and send to the laboratory using ice box.

\section{Sample preparation}

Five to ten grams of meat were mixed with $10 \mathrm{ml}$ of peptone $(0.1 \%)$ water then homogenized suspension was prepared using sterilized pestle and mortar.

\section{Isolation and identification of $E$. coli}

The homogenized samples were then transferred into nutrient broths $(5 \mathrm{ml} /$ test tube), nutrient agar and others specific media (EMB agar and SS agar, Hi-media, India). In every step, samples were incubated at $37^{\circ} \mathrm{C}$ for 24 hours. The positive samples were then subculture several times to be pure culture. Gram staining and Biochemical test (five basic sugars) were done to be confirmed (Cheesbrough, 1985). Antibiotic disc diffusion (CLSI, 2012) test were done for E. coli in Muller- Hinton agar (Hi-Media, India).

\section{Polymerase chain reaction $(\mathbf{P C R})$}

DNA extractions were performed through boiling method (Hassan et al., 2012). PCR assay were applied in all the 64 isolates to confirm the $E$. coli. For the detection of $E$. coli a highly conserved region such as $16 \mathrm{~S}$ rRNA was targeted. The nucleotide sequence (5'-3') of the primer ECO-1Foward GACCTCGGTTTAGTTCACAGA and ECO1ReverseCACACGCTGACGCTGACCA with amplicon size 585 bp (Fratamico et al., 2000) were used. PCR reaction mixture for single sample were $20 \mu \mathrm{l}$ consisting of RNAse free water $5 \mu \mathrm{l}$, PCR master mixture (Thermo Scientific, EU) $10 \mu \mathrm{l}$, genomic DNA $3 \mu \mathrm{l}$ and primer $2 \mu \mathrm{l}$. The PCR amplification was done by Initial denaturation at $94^{\circ} \mathrm{C}$ for 3 minutes followed by 35 cycle of denaturation at $94^{\circ} \mathrm{C}$ for 45 second, annealing at $55^{\circ} \mathrm{C}$ for $45 \mathrm{sec}$ and extension at $72^{\circ} \mathrm{C}$ for 60 secon. The final extension was at $72^{\circ} \mathrm{C}$ for $7 \mathrm{~min}$. PCR amplify products were subjected to gel (1\% agarose, Takara, Japan) electrophoresis with ethidium bromide fluorescence (100 v for 30 minutes) and visualized in gel documentation system via UV transilluminator $(302 \mathrm{~nm})$.

\section{Detection of multi-drug resistant $E$. coli Antimicrobial sensitivity test}

Antimicrobial susceptibility of $E$. coli was performed by the disc diffusion test applied on Muller-Hinton agar (Hi-media, India) in vitro using 10 commercially available antibiotics (Oxoid, UK) e. g., oxytetracycline $(30 \mu \mathrm{g})$, ciprofloxacin $(5 \mu \mathrm{g})$, gentamicin $(10 \mu \mathrm{g})$, erythromycin, $(15 \mu \mathrm{g})$, azithromycin $(15 \mu \mathrm{g})$, sulphonamide-trimethoprim $(25 \mu \mathrm{g})$, neomycin $(10 \mu \mathrm{g})$, amoxicillin $(10 \mu \mathrm{g})$, doxycycline $(10 \mu \mathrm{g})$ and amikacin $(30 \mu \mathrm{g})$ according to the guidelines of the CLS1 (2012).

\section{RESULTS}

Prevalence

Based on cultural, staining and biochemical characteristics, the overall prevalence of E. coli in food was $37.86 \%$ and in milk $29.63 \%$, chicken meat $49.02 \%$ and in beef $70 \%$ (Table 1 ).

Table 1. Prevalence of E. coli in food

\begin{tabular}{llllc}
\hline Food Samples & Milk & Chicken meat & Beef & Total \\
\hline No. of samples tested & 108 & 51 & 10 & 169 \\
No. of culture positive samples & 32 & 25 & 07 & 64 \\
Prevalence $(\%)$ & 29.63 & 49.02 & 70 & 37.86 \\
\hline
\end{tabular}




\section{Cultural, staining and biochemical characteristics}

Cultural colony characteristics showed that $E$. coli produces turbid growth on nutrient broth and smooth white to grayish white colony on nutrient agar with peculiar fetid odor, dark with metallic sheen on EMB agar and slight pinkish smooth colonies on SS agar. On Gram staining E. coli were found Gram negative short rods and arranged as single, paired or in short chain. The five basic sugars e. g., dextrose, maltose, lactose, sucrose and mannitol were fermented by most of the isolates producing acid and gas but few isolates fermented all basic sugar except sucrose.

\section{Molecular detection}

The result of PCR is presented in Figure 1. The amplified size of PCR product was 585 bp indicated or reconfirmed as E. coli isolate in the food samples.

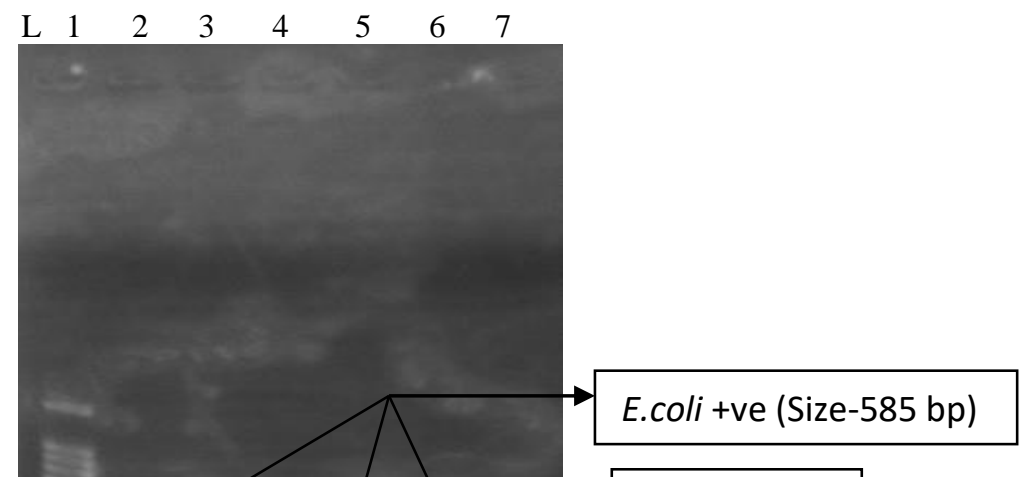

$500 \mathrm{bp}$ of ladder
Figure 1. Amplification of PCR product; Lane:1:100 bp ladder, Lane 3,5,6: Specific for E.coli (Size-585 bp). Lane 2, 4 and 7 negative

\section{Antibiogram study}

The results of antibiotic sensitivity test have been shown in Table 2. E. coli isolates of chicken meat were highly resistant to oxytetracycline (92\%) followed by sulphonamide-trimethoprim (84\%), amoxycillin (76\%), erythromycin $(60 \%)$. E. coli isolates of beef samples were highly resistant to ciprofloxacin and gentamicin (100\%) followed by erythromycin (86\%) and oxytetracycline (71\%). All isolates of E. coli were highly sensitive to amikacin. E. coli isolates of milk samples were highly sensitive to gentamicin (100\%) followed by ciprofloxacin, neomycin, azithromycin, oxytetracycline and erythromycin. But they were resistant to amoxicillin (50\%), followed by sulphonamide-trimethoprime $(47 \%)$, doxycycline $(44 \%)$.

Table 2. Antibiogram study of E. coli isolates from different food samples

\begin{tabular}{lllllll}
\hline Antibiotics & \multicolumn{2}{l}{ Chicken meat $(\mathrm{n}=25)$} & Milk $(\mathrm{n}=32)$ & & \multicolumn{2}{l}{ Beef $(\mathrm{n}=07)$} \\
\hline & Resistant $(\%)$ & Sensitive $(\%)$ & Resistant $(\%)$ & Sensitive $(\%)$ & Resistant $(\%)$ & Sensitive $(\%)$ \\
\hline Oxytetracycline & $23(92)$ & $2(8)$ & $05(33.33)$ & $10(66.67)$ & $05(71.43)$ & $2(28.57)$ \\
Ciprofloxacin & $11(44)$ & $14(56)$ & $05(15.63)$ & $27(84.38)$ & 0 & $7(100)$ \\
Gentamicin & $04(16)$ & $21(84)$ & 0 & $32(100)$ & 0 & $7(100)$ \\
Erythromycin & $15(60)$ & $10(40)$ & $13(40.63)$ & $19(59.38)$ & $06(85.71)$ & $1(14.29)$ \\
Azithromycin & $08(32)$ & $17(68)$ & $09(28.13)$ & $23(71.88)$ & $02(28.57)$ & $5(71.43)$ \\
Sulphonamide & $21(84)$ & $4(16)$ & $15(46.88)$ & $17(53.13)$ & $02(28.57)$ & $5(71.43)$ \\
and & & & & & & \\
Trimethoprim & & & & & & \\
Neomycin & $02(08)$ & $23(92)$ & $02(6.25)$ & $30(93.75)$ & 0 & $7(100)$ \\
Amoxycillin & $19(76)$ & $6(24)$ & $16(50)$ & $16(50)$ & $03(42.86)$ & $4(57.14)$ \\
Doxycycline & $12(48)$ & $13(52)$ & $14(43.75)$ & $18(56.25)$ & $02(28.57)$ & $5(71.43)$ \\
Amikacin & 0 & $11(100), \mathrm{n}=11$ & 0 & $6(100), \mathrm{n}=6$ & 0 & $7(100)$ \\
\hline
\end{tabular}

The prevalence of multi-drug resistant E. coli isolated from different food samples was presented in Table 3. About $50 \%$ of the total isolates of $E$. coli were multi-drug resistant. However, $76 \%$ of the chicken meat E. coli isolates was multidrug resistant. 


\section{A. Rahman and others}

Table3. The prevalence of multi-drug resistant $E$. coli isolates

\begin{tabular}{lllll}
\hline Antibiogram applied & Milk & Chicken meat & Beef & Total \\
\hline No. of E. coli isolates & 32 & 25 & 07 & 64 \\
Multi-drug resistant & 09 & 19 & 04 & 32 \\
Overall prevalence (\%) & 28.13 & 76.0 & 57.14 & 50.0 \\
\hline
\end{tabular}

\section{DISCUSSION}

The overall prevalence of $E$. coli in foods of animal origin was 37.86\%. Jakaria et al., (2012) reported a higher prevalence of $78.86 \%$ in cloacal sample of chicken. Rahman et al. (2004) reported a prevalence of $21.09 \%$ in dead or moribund chicken. Barua et al., (2007) reported that the highest prevalence of $E$. coli was observed in ready-to-eat (RTE) milk products (76\%), followed by RTE meat products $(35.21 \%)$. This variation in prevalence with current study might be due to the variation in the selection of sample. Arslan and Ayi (2011) reported $42.9 \%$ prevalence from retail meat sample including chicken meat. Our results indicate that there is a high prevalence of $E$. coli in chicken meat, milk and beef which suggest that the production and processing of these foods are not hygienic. The farmers and people involved in every stage of food production and processing should be educated about food hygiene. Relatively higher numbers of $E$. coli isolates were obtained in conventional method (37.87\%) than molecular technique (35.94\%). Similar finding was also reported by Koskinen et al. (2010) who reported culture identified a species not targeted by the PCR test in 44 samples from clinical mastitis and in 9 samples from subclinical mastitis and dissimilar with Salauddin (2015) who reported all isolates of $E$. coli were $16 \mathrm{~S}$ rRNA positive.

Multi- drug resistant $E$. coli isolates were found for 10 commonly used and market available antibiotics. Although we did not check the pathogenicity of the isolates, the gene responsible for multi-drug resistance may transfer to consumer via food and results in serious public health hazard as because Boarlin et al., (2005) reported antimicrobial resistance is more frequent in pathogenic than in other porcine E. coli strains, and also shows that the resistance genes found in ETEC isolates are different from those of other porcine $E$. coli isolates and that clear associations exist between specific resistance and virulence genes. Jhonson et al. (2007) also reported that the drug resistant human isolates were similar to poultry isolates and thus, concluded that many drug-resistant human fecal E. coli isolates may be originated from poultry. This resistance occurs due to possessing of resistant gene found in single and multiple size plasmids in $E$. coli isolates.

The highest prevalence of multi-drug resistant E. coli isolates was obtained from chicken meat 76\%. Adesiyun et al. (2007) reported E. coli which was resistant to at least three or more antimicrobial agents. Álvarez-Fernández et al. (2013) reported that $91.7 \%$ E. coli isolates of poultry were multi-drug resistant. Indiscriminate use, improper selection, improper dose, incorrect duration of antibiotics at flock level may be responsible for such a higher occurrence of MDR. Hassan et al. (2013) reported $22.7 \%$ MDR E. coli isolates from bird samples.

In our study, about $92 \%$ of $E$. coli isolates of chicken meat were resistant to oxytetracycline followed by sulphonamide and trimethoprim (84\%), amoxycillin (76\%), erythromycin (60\%). Smith et al. (2007) also reported similar findings. Jhonson et al. (2007) stated that E. coli isolates in poultry were resistant to trimethoprim-sulphamethoxazole, quinolones and cephalosporins. Oxytetracycline and potentiated sulphonamides are commonly used antibiotics in Bangladesh. Hence in therapeutic decision these drugs should be used with caution and only after antibiotic sensitivity testing.

Almost $100 \%$ of the E. coli isolated from beef samples were resistant to ciprofloxacin and gentamicin followed by erythromycin $(86 \%)$ and oxytetracycline (71\%) which is similar to the findings of Jhonson et al. (2007). Similarly, use of ciprofloxacin and gentamicin (widely used antibiotics in both cattle and poultry practice) should be done only after sensitivity testing.

All isolates of $E$. coli were highly sensitive to amikacin which differ with the findings of Arya et al. (2008) who reported that STEC strains are resistant to amikacin (80\%), tetracycline (63\%), ciprofloxacin (20\%). Amikacin is a recently introduced drug in poultry farm. Rationale use of this drug may prevent development of resistant isolates of $E$. coli in future. E. coli isolates of milk sample were highly sensitive to gentamicin followed by ciprofloxacin, neomycin, azithromycin, oxytetracycline and erythromycin. Miles et al. (2006) reported that E. coli isolates were resistant to tetracycline $(82.4 \%)$ which is similar to our result.

E. coli isolated from beef sample were highly sensitive to ciprofloxacin, gentamicin and neomycin which are supported by the findings of Hossain et al. (2008).

\section{CONCLUSIONS}

The higher prevalence of $E$. coli in milk, chicken meat and beef indicates unhygienic production and processing of these foods. Presence of multi-drug resistant $E$. coli in these foods may pose serious public health threats. The antibiogram profile of the isolates may help therapeutic decision making in cattle and poultry practice in Bangladesh. Further studies on pathogenicity and detection of antibacterial resistant genes as well as genetic evolution can be performed. 
ACKNOWLEDGEMENT

Antimicrobial resistance of Escherichia coli

The authors are grateful to Ministry of Education, The People's Republic of Bangladesh for the financial support of this study (Project No.267/2015 MoE).

\section{REFERENCES}

1. Adesiyun A, Offiaha N, Seepersadsingha N, Rodrigoa S, Lashley V and Musai L (2007). Antimicrobial resistance of Salmonella spp. and Escherichia coli isolated from table eggs. Food Control 18: 306-311.

2. Álvarez-Fernández E, Cancelo A, Díaz-Vega C, Capita R and Alonso-Calleja C (2013). Antimicrobial resistance in E. coli isolates from conventionally and organically reared poultry: A comparison of agar disc diffusion and sensi test Gramnegative methods. Food Control 30: 227-234.

3. Arslan A and Eyi A (2011). Antimicrobial resistance and ESBL prevalence in Escherichia coli from retail meats. Journal of Food Safety 31: 262-267.

4. Arya G, Roy A, Choudhary V, Yadav MM and Joshi CG (2008). Serogroups, atypical biochemical characters, colicinogeny and antibiotic resistance pattern of shiga toxin-producing Escherichia coli isolated from diarrhoeic calves in Gujarat, India. Zoonoses and Public Health 55: 89-98.

5. Badrul H, Linus S, Asa M, Mirva D, Jorge H, Jonas W, Munirul A and Bjorn O (2012) Antimicrobial drug-resistant Escherichia coli in wild birds and free-range poultry, Bangladesh. Emerging Infectious Diseases 18: 2055-2058.

6. Barua R, Bhilegaonkar KN, Agarwal RK, Singh DK, Malik SVS, Rathore RS, et al. (2007). Prevalence and rapid detection of shiga toxin producing E. coli (STEC) in water and ready-to-eat (RTE) foods. Journal of Veterinary Public Health 5: 75-83.

7. CDC (2005). What is an antibiotic? In: National Antimicrobial Resistance Monitoring System (NARMS), Department of Health and Human Services. (Centers for Disease Control and Prevention). Frequently asked questions about antibiotic resistance. Atlanta, USA. (http://www.cdc.gov/narms/faq_pages, accessed on 16 August, 2007).

8. CLSI (Clinical Laboratory Standard Institute) (2012). Performance standards for antimicrobial disk susceptibility tests: approved standard. $11^{\text {th }}$ ed. Wayne: CLSI Publication M2-A11.

9. White DG, Zhao S, Simjee S, Wagner DD, McDermott PF (2002). Antimicrobial resistance of foodborne pathogens. Microbes and Infection 4: 405-412.

10. Fratamico PM, Bagi LK and Pepe T (2000).A multiple polymerase chain reaction assay for rapid detection and identification of Escherichia coli 0157: H7 in foods and bovine feces. Journal of Food Protection 63: 1032-1037.

11. Hassan M and Alireza J (2013). Shiga toxin-producing Escherichia coli isolated from chicken meat in Iran: Serogroups, virulence factors, and antimicrobial resistance properties. Poultry Science 92: 1305-1313.

12. Hassan M, Farhad SD,Taktaz T, Rezvani A and Yarali S (2012) Shiga toxin-producing Escherichia coli isolated from bovine mastitic milk: serogroups, virulence factors, and antibiotic resistance properties. The Scientific World Journal Article ID 618709,9 pages.

13. Hossain MT, Siddique MP, Hossain FMA, Zinnah MA, Hossain MM, Alam MK, Rahman MT and Choudury KA (2008). Isolation, identification, toxin profile and antibiogram of Escherichia coli isolated from broilers and layers in Mymensingh district of Bangladesh. Bangladesh Journal of Veterinary Medicine 6: 1-5.

14. Islam MA, Mondol AS, Azmi IJ, Beumer RR and Zwietering MH (2010). Occurrence and characterization of shiga-toxin producing Escherichia coli in raw meat, raw milk, and street vended juices in Bangladesh. Foodborne and Pathogenic Diseases 7: 1381-1385.

15. Jakaria ATM, Islam MA and MM Khatun (2012). Prevalence, characteristics and antibiogram profiles of Escherichia coli isolated from apparently healthy chickens in Mymensingh, Bangladesh. Microbes and Health 1: 27-29.

16. Johnson JR, Sannes MR, Croy C, Johnston B, Clabots C and Kuskowski MA (2007). Antimicrobial drug-resistant Escherichia coli from humans and poultry products, Minnesota and Wisconsin, 2002-2004. Emerging Infectious Disease 13: 838-846.

17. Khan AA, Nawaz MS, Summage West C, Khan SA and Lin J (2005). Isolation and molecular characterization of fluoroquinolone-resistant Escherichia coli from poultry litter. Poultry Science 84: 61-66.

18. Koskinen MT, Wellenberg GJ, Sampimon OC, Holopainen J, Rothkamp A, Almikivi LS, Haeringen van WA, Lam TJGM and Pyorala S (2010). Field comparison of real-time polymerase chain reaction and bacterial culture for identification of bovine mastitis bacteria. Journal of Dairy Science 93: 5707-5715.

19. Quigley L, O'Sullivan O, Stanton C, Beresford TP, Ross RP, Fitzgerald GF and Cotter PD (2013). The complex microbiota of raw milk. FEMS Microbiology 37: 664-698.

20. Miles TD, McLaughlin W and Brown PD (2006). Antimicrobial resistance of Escherichia coli isolates from broiler chickens and humans. BMC Veterinary Research 2: 7-16.

21. Zeinhoma MMA and Abdel-Latef GK (2014). Public health risk of some milk borne pathogens. Beni Suef University Journal of Basic and Applied Science 1-7.

22. Pesavento G, Ducci B, Comodo N and Nostro AL (2007). Antimicrobial resistance profile of Staphylococcus aureus isolated from raw meat: a research for methicillin resistant Staphylococcus aureus (MRSA). Food Control 18: 196-200.

23. Rahman MA, Samad MA, Rahman MB and Kabir SML (2004). Bacteriopathological studies on salmonellosis, colibacillosis and pasteurellosis in natural and experimental infections in chickens. Bangladesh Journal of Veterinary Medicine 2: 01-08. 
24. Salauddin (2015). Isolation, Molecular identification and antibiogram profiles of Campylobacter sp. Salmonella sp. and Escherichia coli from broiler meat sold in different upazilla markets of Mymensingh, Sherpur and Gazipur districts. MS in Food hygiene. Thesis submitted to the Dept. of Microbiology and hygiene. Bangladesh Agricultural University, Mymensingh.

25. Samad MA (2011). Public health threat caused by zoonotic diseases in Bangladesh. Bangladesh Journal of Veterinary Medicine $9: 95-120$

26. Scallan E, Hoekstra RM, Angulo FJ, Tauxe RV, Widdowson MA, Roy SL, Jones JL and Griffin PM (2011). Foodborne illness acquired in the United States-major pathogens. Emerging Infectious Diseases 17: 7-15.

27. Sharada R, Wilfred Ruban S and Thiyageeswaran M (2010). Isolation, characterization and antibiotic resistance pattern of Escherichia coli isolated from poultry. American-Eurasian Journal of Scientific Research 5: 18-22.

28. Shivani C, Khurana SK and Mane BG (2014). Escherichia coli: Animal Foods and Public Health-Review. Journal of Microbiology, Immunology and Biotechnology 1: 31-46.

29. Smith JL, Drum DJ, Dai Y, Kim JM, Sanchez S, Maurer JJ, Hofacre CL and Lee MD (2007). Impact of antimicrobial usage on antimicrobial resistance in commensal Escherichia coli strains colonizing broiler chickens. Applied and Environmental Microbiology 73: 1404-1414.

30. WHO (2006). WHO consultation to develop a strategy to estimate the global burden of foodborne diseases: taking stock and charting the way forward, World Health Organisation, Geneva.

31. WHO (2007a). WHO: Food safety and food borne illness. World Health Organisation, Geneva.

32. WHO (2007b). World Health Organization: Food Safety - Foodborne diseases and value chain management for food safety. ("Forging links between agriculture and Health" CGIAR on Agriculture and Health Meeting in WHO/HQ). World Health Organisation. 